\title{
A prospective multicentre study of barriers to discharge from inpatient rehabilitation
}

\section{Peter W New MB BS, MClinEpi FAFRM(RACP) PhD Candidate, Rehabilitation Medicine Physician, ${ }^{2}$ and Principal Researcher $^{3}$ \\ Damien J Jolley MSc(Epidemiol) MSc, A Stat, Associate Professor and Senior Biostatistician Centre of Research Excellence in Patient Safety \\ Peter A Cameron MB BS, MD, FACEM Professor, and Head of Critical Care Research Division \\ John Hover MB BS, MD, FAFRM(RACP), Professor, Director and Rehabilitation Medicine Physician $^{3}$ \\ Johannes U Stoelwinde MB BS, MD, FRACMA, Chair of Health Services Management \\ 1 Department of Epidemiology and Preventive Medicine, Monash University, \\ Melbourne, VIC \\ 2 Southern Health \\ Melbourne, VIC. \\ 3 Epworth-Monash Rehabilitation Medicine Unit, Monash University, \\ Melbourne, VIC \\ Peter.new@ southernhealth.org.au}

MJA 2013; 198: 104-108 doi: 10.5694/mjal2.10340

\section{T} he occurrence of "exit block" from acute hospital to rehabilitation has been noted, but there has been little formal study of discharge barriers in rehabilitation. ${ }^{1-3}$ Discharge barriers in rehabilitation have an adverse impact "upstream", with flow-on effects that limit acute hospital bed availability. A recent study highlighted rehabilitation discharge barriers as a major concern among clinicians and hospital managers in Australia. ${ }^{3}$ Identifying and addressing these would be an important opportunity for improving hospital efficiency.

The objectives of this study were: 1) to measure the proportion of rehabilitation patients with a discharge barrier, 2) to record the causes of discharge barriers, and their duration, and 3) to determine whether any demographic or clinical variables predicted the discharge barriers or the number of additional days in hospital.

\section{Methods}

\section{Study design and setting}

We conducted a prospective open cohort study of consecutive patients admitted for inpatient rehabilitation into two acute "fast stream" rehabilitation units (South 4, Kingston Centre, and South West 2, Dandenong Hospital) in Southern Health, the largest public hospital network in Victoria. At Kingston Centre, the study commenced on 1 January 2008, while at Dandenong Hospital, the study commenced on 1 March 2008 (the starting dates were different because of the logistics involved in running the study).

The two units had a total of 48 inpatient beds for managing a range of neurological conditions (eg, acquired brain injury such as stroke, subarachnoid haemorrhage and traumatic brain injury, and other conditions), orthopaedic conditions (eg, arthroplasty and lower limb fractures, typically from falls - very rarely from motor vehicle accidents) and decon-

\begin{abstract}
Objectives: To assess the prevalence of and reasons for barriers to discharge from inpatient rehabilitation, to measure the resulting additional days in hospital, and to determine if these were predicted by key demographic or clinical
\end{abstract} variables.

Design, setting and participants: Prospective open cohort study of 360 patients admitted into two inpatient rehabilitation units in Melbourne over an 8-month and a 10-month period in 2008.

Main outcome measures: Occurrence of discharge barriers, their causes and the duration of unnecessary hospitalisation.

Results: There were 360 patients in the study sample, 186 were female (51.7\%), and mean age was 58.4 years. Fifty-nine (16.4\%) patients had a discharge barrier. The most frequent causes of discharge barriers were patients being nonweight bearing after lower limb fracture, family deliberations about discharge planning, waiting for home modifications and waiting for accommodation. Patients with acquired brain damage and lower limb fracture were the impairment groups most likely to experience a discharge barrier. Over the study period, $21.0 \%$ (3152/14976) of all bed-days were occupied by patients deemed to have a discharge barrier. Regression analysis showed that age, sex, impairment group and dependency level on admission all influenced the occurrence of a discharge barrier. Although regression analysis showed that dependency on admission and age group were significant predictors of additional days in hospital resulting from discharge barriers $(P=0.006)$, these variables explained only $11 \%$ of the additional bed-days.

Conclusion: Barriers to discharge from inpatient rehabilitation are common and substantial, and they represent an important opportunity for improvement.

ditioning after severe and acute illnesses, including cardiac and pulmonary conditions.

The rehabilitation units provide therapy (typically $2-3$ hours a day) for patients with moderate to severe disability who cannot be discharged directly to their home from acute hospital care, and who require an interdisciplinary inpatient rehabilitation program. Patients are admitted for rehabilitation after any necessary acute medical or surgical treatments are completed, and when they are deemed stable by both the acute hospital staff and the rehabilitation assessment service.

\section{Participants}

We included all patients admitted from the two project commencement dates to 31 October 2008. Patients who remained in hospital beyond 31 October 2008 were monitored until discharge. Any patients who were transferred back to an acute hospital for elective or emergency treatment during the course of their rehabilita- tion and who were subsequently readmitted back into rehabilitation were considered as continuing their initial admission, rather than starting a separate admission. Patients were excluded if their admission was elective from the community or if they were discharged on the day of admission.

Discharge decisions were made with the involvement of the patient and their family. The treating team strived for the shortest length of stay (LOS) that would allow patients to be discharged to the least restrictive environment (always aiming for the previous accommodation) with the necessary care, equipment and home modifications for a safe discharge.

\section{Variables}

We recorded the following data for each patient: principal impairment necessitating rehabilitation, date of birth, date of admission, sex, rehabilitation LOS (excluding any days transferred back to acute hospital), and the patient's level of dependency 
1 Classification of the causes of discharge barriers*t in a sample of 360 rehabilitation inpatients, proportion of patients affected by each type of discharge barrier and associated additional unnecessary days in hospital ${ }^{\ddagger}$

\begin{tabular}{|c|c|c|c|}
\hline Causes of discharge barriers ${ }^{\dagger}$ & $\begin{array}{l}\text { Patients } \\
\text { with discharge } \\
\text { barrier }\end{array}$ & $\begin{array}{l}\text { Additional } \\
\text { unnecessary } \\
\text { days in hospital }\end{array}$ & $\begin{array}{l}\text { Median (IQR) } \\
\text { additional } \\
\text { unnecessary } \\
\text { days in hospital }\end{array}$ \\
\hline $\begin{array}{l}\text { Non-weight-bearing: Patient non-weight-bearing after lower limb fracture(s). No longer needing inpatient } \\
\text { rehabilitation therapy because of lack of benefit in improving function in mobility and transfers. Team } \\
\text { recommends maintenance therapy until able to increase weight-bearing; however, no alternative setting of care } \\
\text { available, and patient unable to return to the community. }\end{array}$ & $20(5.6 \%)$ & $1390(44.1 \%)$ & $43.5(34.5-75.5)$ \\
\hline $\begin{array}{l}\text { Family: Negotiations and discussions with family members regarding discharge planning issues that delay } \\
\text { discharge processes. In particular, but not limited to, whether family will provide care for the patient or whether } \\
\text { the patient will be discharged to a care facility. }\end{array}$ & $13(3.6 \%)$ & $409(13.0 \%)$ & $24(13-31)$ \\
\hline Accommodation: Patient has no available suitable accommodation options. & $12(3.3 \%)$ & $287(9.1 \%)$ & $16.5(10.5-37)$ \\
\hline $\begin{array}{l}\text { Home modifications: Patient waiting for home modifications that are essential to ensure safe access and care at } \\
\text { home after discharge. Includes funding and completion of modifications. }\end{array}$ & $9(2.5 \%)$ & $713(22.6 \%)$ & $34(16-132)$ \\
\hline $\begin{array}{l}\text { Long-term and supported care or services and equipment assessment/approval: Patient referred to a service or } \\
\text { organisation for confirmation of appropriateness and necessity of supported care (nursing home or hostel) or } \\
\text { long-term services or equipment. Includes waiting for the assessment; determination of level of care or range of } \\
\text { services and equipment; related paperwork; and where relevant, confirmation that no option available for } \\
\text { alternative care, where this process is required. }\end{array}$ & $7(1.9 \%)$ & $78(2.5 \%)$ & $12(6-15)$ \\
\hline \multicolumn{4}{|l|}{$\begin{array}{l}\text { Ambulatory rehabilitation: Patient waiting for assessment and/or availability of ambulatory rehabilitation } \\
\text { services and no longer needing intensity of inpatient rehabilitation, but the team feels patient is not able to be } \\
\text { discharged until ambulatory rehabilitation is confirmed and available. }\end{array}$} \\
\hline Southern Health network & $7(1.9 \%)$ & $53(1.7 \%)$ & $7(5-10)$ \\
\hline Other health networks & $1(0.3 \%)$ & $4(0.1 \%)$ & $4(\mathrm{na})$ \\
\hline Carer funding: Patient waiting for funding for carers to ensure safe care after discharge. & $6(1.7 \%)$ & $479(15.2 \%)$ & $93(6-135)$ \\
\hline Carer recruiting and training: Waiting for recruiting and training of carers to ensure safe care after discharge. & $5(1.4 \%)$ & $118(3.7 \%)$ & $15(12-30)$ \\
\hline $\begin{array}{l}\text { Equipment: Delay waiting for necessary equipment to be available, after specific equipment needs have been } \\
\text { identified and prescribed, that is essential to ensure safe care after discharge. Includes funding and supply of } \\
\text { equipment. }\end{array}$ & $4(1.1 \%)$ & $240(7.6 \%)$ & $45(10-110)$ \\
\hline $\begin{array}{l}\text { Specialist review: Patient requires medical or surgical review to determine critical changes in his/her } \\
\text { management deemed necessary to delay discharge planning process. }\end{array}$ & $4(1.1 \%)$ & $46(1.5 \%)$ & $9(1-22)$ \\
\hline \multicolumn{4}{|l|}{$\begin{array}{l}\text { Alternative setting of care: Waiting for high-level (nursing home) or low-level (hostel, supported residential } \\
\text { service) residential care accommodation to be available. }\end{array}$} \\
\hline High-level care accommodation & $3(0.8 \%)$ & $108(3.4 \%)$ & $26(10-72)$ \\
\hline Low-level care accommodation & $2(0.6 \%)$ & $34(1.1 \%)$ & $17(16-18)$ \\
\hline $\begin{array}{l}\text { Occupational therapy home assessment: Patient no longer needs inpatient rehabilitation, but home visit not yet } \\
\text { conducted and believed to be necessary before discharge to confirm and optimise safe access and internal } \\
\text { environment. }\end{array}$ & $2(0.6 \%)$ & $21(0.7 \%)$ & $10.5(7-14)$ \\
\hline $\begin{array}{l}\text { Guardian/power of attorney appointment: Application made for determining power of attorney or guardian for } \\
\text { making a decision that is blocking discharge planning, and patient not competent and no nominated person } \\
\text { existing. Also includes subsequent delay in decisions being made by nominated guardian regarding discharge } \\
\text { planning. }\end{array}$ & $2(0.6 \%)$ & $62(2.0 \%)$ & $31(14-48)$ \\
\hline $\begin{array}{l}\text { Competency assessment: Patient requires neuropsychology assessment for competency in decision making } \\
\text { before proceeding with discharge options. }\end{array}$ & $1(0.3 \%)$ & $10(0.3 \%)$ & $10($ na) \\
\hline Other causes & $1(0.3 \%)$ & $13(0.4 \%)$ & $13(n a)$ \\
\hline
\end{tabular}

IQR = interquartile range. na $=$ not applicable.

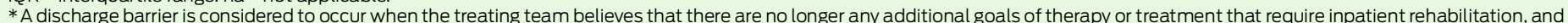

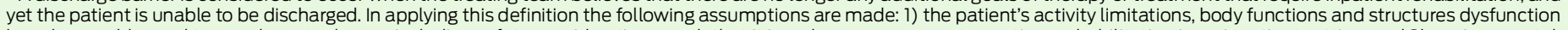

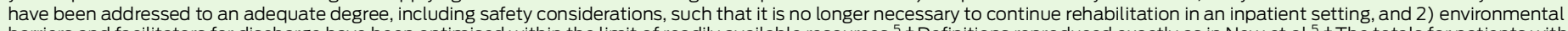

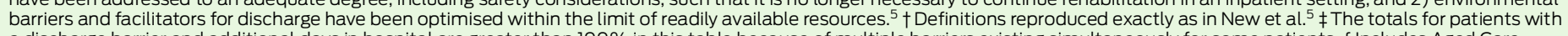

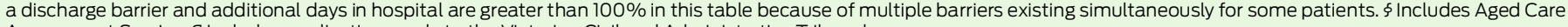
Assessment Service. Я Includes application made to the Victorian Civil and Administrative Tribunal.

in self-care, continence and mobility at the time of admission and discharge using the Modified Barthel Index (MBI). ${ }^{4}$ The MBI provides a scale from 0 to 100 , with $0=$ total incapacity and $100=$ independent. The main outcome variables were the occurrence of a discharge barrier, its cause(s), and the number of additional unnecessary days in hospital resulting from the discharge barrier (from the onset of the barrier until resolution). When multiple discharge barriers occurred simultaneously, any overlapping days were eliminated from the regression analysis and total unnecessary days in hospital were reported. The definition of a discharge barrier and classification of causes (Box 1) were based on our recently published work. ${ }^{5}$

\section{Data sources}

The occurrence of a discharge barrier, the cause(s), and date of onset or resolution were noted during the twice-weekly ward rounds and confirmed at weekly team meetings. Data analysis was performed using Stata 11 for Windows (StataCorp).

\section{Statistical methods}

For variables that were normally distributed (eg, age), the mean and standard deviation were calculated. For continuous variables that were not normally distributed (eg, LOS), the median and interquartile range (IQR) were reported. The relationship between the occurrence of a discharge barrier and categorical variables was calculated using the $\chi^{2}$ test. 
2 Key impairment groups, patient age, level of dependency and proportion of patients with a discharge barrier in a sample of 360 rehabilitation inpatients

\begin{tabular}{|c|c|c|c|c|c|c|c|c|c|c|}
\hline $\begin{array}{l}\text { Key impairment } \\
\text { group }\end{array}$ & Patients & $\begin{array}{l}\text { Mean age* } \\
\text { (SD) }\end{array}$ & $\begin{array}{c}\text { Median MBI } \\
\text { dependency } \\
\text { score on } \\
\text { admission } \\
\text { (IQR) }\end{array}$ & $\begin{array}{c}\text { Median MBI } \\
\text { dependency score } \\
\text { on discharge } \\
\text { (IQR) }\end{array}$ & $\begin{array}{c}\text { Patients } \\
\text { with a discharge } \\
\text { barrier }^{\delta}(\%) \\
95 \% \mathrm{Cl}\end{array}$ & $\begin{array}{l}\text { Odds ratio of } \\
\text { discharge } \\
\text { barrier } \\
(95 \% \mathrm{Cl})\end{array}$ & $\chi^{2}$ & $P$ & $\begin{array}{l}\text { Median length } \\
\text { of stay** (IQR) }\end{array}$ & $\begin{array}{l}\text { Mean additional } \\
\text { unnecessary days } \\
\text { in hospital }\end{array}$ \\
\hline $\begin{array}{l}\text { Stroke, SAH or } \\
\mathrm{TBI}^{\ddagger \ddagger}\end{array}$ & $64(17.8 \%)$ & $55.2(14.4)$ & $17(1-36)$ & $75.5(25-100)$ & $\begin{array}{c}12(20.3 \%) \\
11.0 \%-32.8 \%\end{array}$ & 1 & - & - & $41(16-100)$ & $33(27-93)$ \\
\hline Other neurological & 47(13.0\%) & $49.2(16.0)$ & $28(16-45)$ & 89 (57-99) & $\begin{array}{c}5(8.5 \%) \\
2.8 \%-18.7 \%\end{array}$ & $0.5(0.2-1.5)$ & 1.7 & 0.2 & $30(19-50)$ & $14(7-28)$ \\
\hline $\begin{array}{l}\text { Lower limb } \\
\text { arthroplasty }\end{array}$ & $55(15.3 \%)$ & $64.2(9.8)$ & $38(26-49)$ & $94(82-99)$ & $\begin{array}{c}3(5.1 \%) \\
1.1 \%-14.1 \%\end{array}$ & $0.2(0.06-0.9)$ & 4.9 & 0.03 & $17(13-21)$ & $14(4-34)$ \\
\hline $\begin{array}{l}\text { Lower limb } \\
\text { fracture }\end{array}$ & $60(16.7 \%)$ & $58.8(15.6)$ & $35(19.5-49)$ & 91.5 (70-99) & $\begin{array}{c}18(30.5 \%) \\
19.2 \%-43.9 \%\end{array}$ & $1.8(0.8-4.2)$ & 2.0 & 0.2 & $28.5(17.5-54)$ & $42(16-70)$ \\
\hline $\begin{array}{l}\text { Other musculo- } \\
\text { skeletal }\end{array}$ & $45(12.5 \%)$ & $57.0(14.8)$ & $39(20-47)$ & $94(79-100)$ & $\begin{array}{c}7(11.9 \%) \\
4.9 \%-22.9 \%\end{array}$ & $0.8(0.3-2.2)$ & 0.2 & 0.6 & $22(14-31)$ & $39(8-73)$ \\
\hline $\begin{array}{l}\text { Cardiac or } \\
\text { pulmonary debility }\end{array}$ & $64(17.8 \%)$ & $64.0(13.2)$ & $36(23-48)$ & $97(72.5-100)$ & $\begin{array}{c}8(13.6 \%) \\
6.0 \%-25.0 \%\end{array}$ & $0.6(0.2-1.6)$ & 1.1 & 0.3 & $20(15-33)$ & $23(8.5-65.5$ \\
\hline Other & 25 (6.9\%) & $58.0(16.6)$ & $34(13-45)$ & $99.5(89-100)$ & $\begin{array}{c}6(10.2 \%) \\
3.8 \%-20.8 \%\end{array}$ & $1.5(0.5-4.7)$ & 0.5 & 0.5 & $27(21-52)$ & $19(15-27)$ \\
\hline Total & $360(100 \%)$ & $58.4(15.0)$ & $34(17-47)$ & $93(69-100)$ & 59 (100\%) & - & - & - & $23(15-48.5)$ & $34(14-58.5)$ \\
\hline
\end{tabular}

$\mathrm{IQR}=$ interquartile range. $\mathrm{MBI}=$ Modified Barthel Index. na = not applicable. $\mathrm{SAH}=$ subarachnoid haemorrhage. TBI = traumatic brain injury.

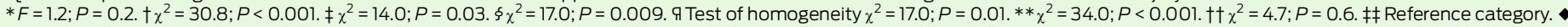

The relationship between normally distributed outcomes was calculated using the Student $t$ test, or the Kruskal-Wallis test for data that were not normally distributed.

We calculated odds ratios for the occurrence of a discharge barrier for the different impairment groups. The influence of patients' age at the time of admission, sex, impairment and the admission MBI on the occurrence of a discharge barrier and the total number of unnecessary days in hospital was assessed using multivariable logistic and linear regressions (backwards inclusion), respectively. The duration of unnecessary hospitalisation was log-transformed to facilitate parametric analysis. Age was categorised into three groups ( $<50$ years, $50-64$ years and $\geqslant 65$ years) corresponding to different age-based criteria for access to programs or services available to patients on discharge.

$P$ values of less than 0.05 were deemed statistically significant. The project was approved by the Southern Health Human Research Ethics Committee and Monash University Human Research Ethics Committee.

\section{Results}

There were 372 patients admitted during the study period, but 12 were excluded (10 had elective admissions from the community and two were discharged on the day of admission), leaving 360 patients in the analysis. There were 186 females (51.7\%) and 174 males $(48.3 \%)$, ranging in age from 16 years to 93 years.

Overall, 59 (16.4\%; 95\% CI, 12.7\%$20.6 \%$ ) patients had a discharge barrier. There was no apparent difference between the participating units and the occurrence of discharge barriers $\left(\chi^{2}=1.5, P=0.2\right)$. Box 2 shows the proportion of patients in different impairment groups, their ages, their LOS, their MBI on admission and discharge, and the proportion with a discharge barrier. The impairment groups most likely to have a discharge barrier were patients with stroke, subarachnoid haemorrhage or traumatic brain injury, and those with lower limb fractures. Among patients with a discharge barrier, 35 had one barrier, 15 had two barriers and nine patients had three or more barriers.

Over the study period $21.0 \%$ (3152/ 14976) of all bed-days were occupied by patients who were deemed to be clinically ready for discharge from rehabilitation but had a discharge barrier. Twenty-five per cent of patients with a discharge barrier spent more than an additional 2 months in rehabilitation, and nine patients had more than 100 additional unnecessary days of hospitalisation (maximum 322 days). The median LOS (58 days; IQR, 32131) for patients with a discharge barrier was significantly greater $(H=47$;
$P<0.001)$ than that of patients who did not have a discharge barrier (median LOS, 21 days; IQR, 14-34).

The causes of discharge barriers and the resulting additional days in hospital are shown in Box 1 . The most common causes of a discharge barrier were patients being nonweight bearing after lower limb fracture, family deliberations about discharge planning, waiting for home modifications and waiting for accommodation. The reasons accounting for the greatest number of additional hospital days were patients being non-weight bearing, home modifications, carer funding, family negotiations, accommodation and equipment necessary for discharge.

Multivariable logistic regression analysis showed that younger patients ( $<50$ years) had significantly greater odds of a discharge barrier than the older group ( $\geqslant 65$ years). Males had significantly greater odds of a discharge barrier than females. Those with lower limb fracture had higher odds compared with those who had a stroke, subarachnoid haemorrhage or traumatic brain injury, and the odds were reduced significantly with lesser dependency on admission (Box 3). Linear regression assessing the variables predicting the number of additional days in hospital showed that being in the younger age group and having greater dependency on admission 
3 Multivariable logistic regression for the occurrence of a discharge barrier in a sample of 360 rehabilitation inpatients

\begin{tabular}{|c|c|c|c|}
\hline Barrier & Odds ratio $(95 \% \mathrm{Cl})$ & $z$ & $P$ \\
\hline \multicolumn{4}{|l|}{ Age group } \\
\hline$<50$ years & $1.0 *$ & -1.5 & 0.1 \\
\hline $51-64$ years & $0.57(0.28-1.19)$ & -3.0 & 0.003 \\
\hline$\geqslant 65$ years & $0.30(0.13-0.66)$ & & \\
\hline \multicolumn{4}{|l|}{ Sex } \\
\hline Male & $1.0 *$ & -2.8 & 0.006 \\
\hline Female & $0.41(0.21-0.77)$ & & \\
\hline \multicolumn{4}{|l|}{ Impairment } \\
\hline Stroke, SAH or TBI & $1.0 *$ & -0.9 & 0.4 \\
\hline Other neurological & $0.60(0.18-1.95)$ & -0.6 & 0.5 \\
\hline Lower limb arthroplasty & $0.64(0.16-2.59)$ & 2.6 & 0.008 \\
\hline Lower limb fracture & $3.65(1.40-9.54)$ & 0.4 & 0.7 \\
\hline Musculoskeletal - other & $1.25(0.41-3.84)$ & 0.4 & 0.7 \\
\hline Cardiac or pulmonary debility & $1.23(0.42-3.55)$ & 1.6 & 0.1 \\
\hline Other & $2.72(0.79-9.44)$ & & \\
\hline Modified Barthels Index on admission & $0.97(0.95-0.99)$ & -3.4 & 0.001 \\
\hline
\end{tabular}

4 Approaches to consider when developing strategies to resolve discharge barriers for rehabilitation patients

- Identifying locus of control over the barrier: internal (rehabilitation team or hospital organisation) or external (other hospital networks, state or federal government)?

- Assessing preventability of the barrier: preventable, potentially preventable or nonpreventable

- Setting priorities in resolving barriers: identifying barriers with the most common causes, those with the greatest contribution to unnecessary hospitalisation, those that are easiest to resolve.

were significant predictors $(P<0.001)$, but these explained only $11 \%$ of the additional days.

\section{Discussion}

We have shown that many rehabilitation patients are in hospital unnecessarily. Patients aged less than 65 years, males, those with lower limb fractures who are non-weight bearing, or those with a brain impairment were more likely to have a discharge barrier. The number of unnecessary bed-days "blocked" by these patients is substantial and represents a significant waste of health care resources. However, a model predicting the number of unnecessary days explained only a small proportion of the total additional unnecessary days in hospital.

We believe the reason that younger patients are more likely to have a discharge barrier is because older patients have more access to services and care options in the community (eg, the Transition Care Program and high-level care). More investigation is needed into why males are more likely to experience a discharge barrier, but this could be related to lack of social supports or other factors. challenge confronting the hospital system, ${ }^{6}$ which will become more pressing with population ageing and increasing chronic disease and disability. ${ }^{7-8}$ Most attention to date has been focused on the emergency department ${ }^{9-11}$ or acute hospitals. ${ }^{12-13}$ No previous studies of discharge barriers in rehabilitation have been identified. In acute hospital general medical patients, the proportion of unnecessary bed-days in the United States $^{13}$ and Australia ${ }^{12}$ has been found to be $14 \%$, which is similar to our results. Others have noted that access to disability-related equipment often does not meet the needs of patients, ${ }^{14}$ as we found here, but the impact of this on rehabilitation LOS has not previously been measured.

When patients are in hospital longer than required for medical reasons, there are a number of potential adverse outcomes. Patients or their families can develop adverse emo-
Efficient patient flow is a major tional reactions. Further, the additional hospitalisation places the patient at risk of iatrogenic complications, including medication errors, nosocomial infections and falls. It has been reported that each additional day in hospital increases the risk of a documented adverse event by $6 \%{ }^{15}$

Rehabilitation is often seen as separate from the acute hospital system. ${ }^{2}$ Although it has been acknowledged that access to rehabilitation is vital for efficient hospital patient flow, ${ }^{2,16}$ a coordinated and holistic view of bed access and patient flow across the whole hospital spectrum has not been present in health care planning and systems change processes to date.

\section{What are the potential solutions for} reducing discharge barriers?

Discharge barriers are complex phenomena, and there are multiple potential approaches to resolving them. Although not all discharge barriers are preventable, many are. Approaches to consider when resolving discharge barriers are shown in Box 4.

Suboptimal implementation of federal-state funding agreements and policies, as well as state-based funding and policies involving aged care, disability, welfare and housing contribute to discharge barriers. At the local level, senior hospital clinical or executive staff can help by resolving internal organisational barriers where this is beyond the ability of the patient's treating team, and by bringing external barriers to the attention of the relevant organisation or government department.

Establishing and communicating the patient's estimated date of discharge and expected destination within a week of admission is one strategy that can potentially help prevent barriers arising from family negotiations. Family negotiations around discharge could also be improved through staff training and increased access to social work and psychological resources. Different models of inpatient rehabilitation could be developed with the involvement of relevant government departments in planning and designing appropriately resourced and flexible models of supportive accommodation, which may be either transitional or permanent. For example, patients 
who are non-weight bearing after lower limb fracture could be provided with lower-cost interim care, where they can also receive maintenance therapy until they are able to start bearing weight, while patients with disabilities who are in hospital should be provided with improved access to suitable permanent accommodation. Making the Transition Care Program ${ }^{17}$ accessible to patients aged less than 65 years would be one potential solution. Improved and timely access to resources for home modification, equipment and carers would go a long way towards resolving discharge barriers. The proposed National Disability Insurance Scheme could solve some of these problems by providing greater and timelier funding than is currently available. ${ }^{18}$

\section{Limitations and generalisability}

The findings of this study should be treated with some caution because patients were sampled for a limited period in two hospitals. However, there were no differences in discharge barriers between the units, suggesting that these problems are unlikely to have resulted from issues within a particular unit. In addition, periodic audits of the occurrence and causes of discharge barriers performed since this project was completed have shown that the problems with discharge barriers remain. Also, it could be argued that there was subjectivity involved in identifying when a discharge barrier occurred and in measuring its duration. This was minimised by having senior rehabilitation team members make consensus decisions about the occurrence and duration of a barrier using an agreed definition of a discharge barrier and categories of causes (Box 1). ${ }^{5}$

We acknowledge that our findings would not be generalisable to private rehabilitation hospitals. Private rehabilitation units are able to be more selective about the patients they admit — tending to have less disabled patients and a shorter LOS compared with rehabilitation units in the public system. ${ }^{19}$ We believe, however, that our results are likely to be generalisable to other public rehabilitation units in Australia. Recent articles in the Journal highlight resource limitations that cause problems with rehabilitation patient discharge as an Australiawide problem. ${ }^{2-3}$ We believe that our results may also be generalisable to international settings. In particular, our findings may be relevant to Canada and Europe, where there are publicly funded hospital systems and challenges with access to adequate social supports and discharge resources, and to other countries with a capped funding scheme (as opposed to fee-per-service funding models of hospital care).

\section{Implications for future practice and research}

More in-depth study of discharge barriers in inpatient rehabilitation is required, including in specialty settings (eg, rehabilitation for patients who are amputees or for patients with a spinal cord injury). Studies with increased numbers of participants and a broader range of measurements would allow adequate power to assess the patterns of different barriers in specific impairment groups, the predictors of specific discharge barriers and the interaction between barriers.

Policymakers and health managers should consider putting more resources into resolving inefficiencies in patient flow through the whole hospital system, not just focusing on the emergency department and acute hospitals. Hospital efficiency cannot be optimised unless rehabilitation is better integrated into the improvement process. Our findings strongly suggest that consideration should be given to directing some of the recently proposed health reform funding for rehabilitation beds ${ }^{20}$ into programs and strategies to address rehabilitation discharge barriers. It is possible that this would be more cost-effective than building and staffing all the proposed rehabilitation inpatient beds.

Acknowledgements: We are grateful to Southern Health for a research grant supporting Peter New's role in this project. We thank Keith Stockman for his inspiration and encouragement to pursue this project. We also thank the following people for their assistance with data collection Regina Hoeppner, Asha Mathew, James Ting, Kapil Gupta, Karen Potter, Hean See Tan, Safa Hamza, Gunendrika Kasthuriratne, Katrina Hidalgo. We appreciate the advice of Nick Andrianopoulos about statistical analysis.

Competing interests: Peter New has received a grant from Southern Health towards this project.

Received 23 Feb 2012, accepted 27 Sep 2012.

1 Victorian Department of Human Services. Subacute/Acute interface project: Final report. Melbourne: Victorian Government, 2001. http:// www.health.vic.gov.au/archive/archive2006/ hdms/subfinal.pdf (accessed Aug 2012).

2 New PW, Poulos CJ. Functional improvement of the Australian health care system - can rehabilitation assist? Med J Aust 2008; 189: 340-343.

3 New PW, Cameron PA, Olver JH, Stoelwinder JU. Inpatient subacute care in Australia: perceptions of admission and discharge barriers. Med J Aust 2011; 195: 538-541.

4 Shah S, Vanclay F, Cooper B. Improving the sensitivity of the Barthel Index for stroke rehabilitation. J Clin Epidemiol 1989; 42: 703-709.

5 New PW, Cameron PA, Olver JH, Stoelwinder JU. Defining barriers to discharge from inpatient rehabilitation, classifying their causes, and proposed performanceindicators for rehabilitation patient flow. Arch Phys Med Rehabil 2013; 94 : 201-208.

6 National Health and Hospitals Reform Commission. A healthier future for all Australiansinterim report December 2008. http://www. health.gov.au/internet/nhhrc/publishing.nsf/ Content/interim-report-december-2008 (accessed Aug 2012).

7 Australian Bureau of Statistics. Disability, ageing and carers, Australia: summary of findings, 2003. Canberra: ABS, 2004. (ABS Cat. No. 4430.0.) http://www.abs.gov.au/AUSSTATS/abs@.nsf/ DetailsPage/4430.02003 (accessed Oct 2012).

8 Schofield DJ, Earnest A. Demographic change and the future demand for public hospital care in Australia, 2005 to 2050. Aust Health Rev 2006; 30: 507-515.

9 Trzeciak S, Rivers EP. Emergency department overcrowding in the United States: an emerging threat to patient safety and public health. Emerg Med J 2003; 20: 402-405.

10 Braitberg G. Emergency department overcrowding: dying to get in? Med J Aust 2007; 187: 624-625.

11 Lowthian JA, Curtis AJ, Jolley DJ, et al. Demand at the emergency department front door: 10-year trends in presentations. Med J Aust 2012; 196: 128-132.

12 Nosworthy J, Campbell D, Byrnes G, Staley C Medical inpatient study report. Melbourne: Melbourne Health, Clinical Epidemiology and Health Service Evaluation Unit, 2001. http://www. health.vic.gov.au/archive/archive2006/hdms/ finmips.pdf (accessed Aug 2012).

13 Carey MR, Sheth H, Braithwaite RS. A prospective study of reasons for prolonged hospitalizations on a general medical teaching service. J Gen Intern Med 2005; 20: 108-115.

14 Bingham SC, Beatty PW. Rates of access to assistive equipment and medical rehabilitation services among people with disabilities. Disabil Rehabil 2003; 25: 487-490.

15 Andrews LB, Stocking C, Krizek T, et al. An alternative strategy for studying adverse events in medical care. Lancet 1997; 349: 309-313.

16 Cameron PA. Hospital overcrowding: a threat to patient safety? Med J Aust 2006; 184: 203-204.

17 Australian Government Department of Health and Ageing. Transition Care Program Guidelines. Canberra: DoHA, 2011. http://www.health.gov.au/ internet/main/publishing.nsf/content/ageingtransition-guidelines.htm (accessed Oct 2012).

18 Australian Government Productivity Commission. Disability care and support. Report no. 54. Canberra: Productivity Commission, 2011. http:// www.pc.gov.au/projects/inquiry/disabilitysupport/report (accessed Aug 2012).

19 Simmonds F, Stevermuer T. The AROC annual report: the state of rehabilitation in Australia 2006. Aust Health Rev 2008; 32: 85-110.

20 National Health and Hospitals Reform Commission. A healthier future for all Australiansfinal report June 2009. http://www.health.gov.au/ internet/nhhrc/publishing.nsf/Content/nhhrcreport (accessed Aug 2012). 